\title{
LIVESTOCK GRAZING REDUCES SOIL QUALITY AND THREATENS RECOVERY OF A DEGRADED ANDEAN ARAUCARIA FOREST.
}

\author{
Oscar Crovo $^{1}$, Clara da Costa-Reidel ${ }^{2}$, Rolando Rodríguez $^{2}$, and Felipe Aburto $^{2}$ \\ ${ }^{1}$ Universidad de Concepción \\ ${ }^{2}$ Universidad de Concepcion
}

March 15, 2021

\begin{abstract}
Araucaria araucana is an iconic long-lived endangered tree species exclusively distributed in Southern Chile and Argentina. Araucaria forest ecosystems provide a myriad of ecosystem benefits to local aboriginal Mapuche-Pehuenche communities. Among the main current threats for Araucaria forests are the increasing frequency and severity of wildfires and overgrazing. This study evaluates the effect of uncontrolled livestock grazing on soil quality indicators linked to critical functions relevant to forest regeneration and ecosystem service provision. We also aim to determine a set of soil quality indicators that are sensitive enough to grazing pressure, so they are useful as early indicators of degradation or the effectiveness of restoration practices. This study evaluated twenty soil quality indicators in two contiguous degraded forest areas with contrasting grazing pressure. We observed a substantial shift in forest structure, a reduction in tree coverage on the overgrazed sites. Overgrazing has produced significant deterioration of most soil physical, chemical, and biological quality indicators making soil conditions less suitable for seed germination and sapling establishment. We also observed an alteration in C, N, and P biogeochemical pools. Besides, soil physical indicators alterations suggest changes in these soils' hydrological behavior, potentially reducing water storage, availability, and increasing runoff. We show that uncontrolled grazing in native protected areas degrades soils and forest health, restricting forest regeneration and potentially accelerating erosive processes. Our results emphasized the need for an improved conservation plan for these forests that systematically evaluates and monitors livestock grazing and all its direct and indirect effects, including soil quality.
\end{abstract}

\section{LIVESTOCK GRAZING REDUCES SOIL QUALITY AND THREATENS RECOVERY OF A DE- GRADED ANDEAN ARAUCARIA FOREST.}

Oscar Crovo $^{1}$, Clara da Costa-Reidel ${ }^{1}$, Francisco Montecino ${ }^{1}$, Rolando Rodríguez ${ }^{2}$, Felipe Aburto ${ }^{1 *}$

${ }^{1}$ Laboratorio de Investigación en Suelos, Aguas y Bosques (LISAB). Departamento de Silvicultura, Universidad de Concepción, Facultad de Ciencias Forestales.

${ }^{2}$ Departamento de Manejo de Bosques y Medioambiente, Universidad de Concepción, Facultad de Ciencias Forestales, Concepción, Chile.

* feaburto@udec.cl, Victoria 631, Facultad de Ciencias Forestales, Barrio Universitario, Concepción, Chile

ABSTRACT

Araucaria araucana is an iconic long-lived endangered tree species exclusively distributed in Southern Chile and Argentina. Araucaria forests provide a myriad of ecosystem benefits to local aboriginal MapuchePehuenche communities. Among the main current threats for Araucaria forests are the increasing frequency and severity of wildfires and overgrazing. This study evaluates the effect of uncontrolled livestock grazing 
on soil quality indicators linked to critical functions relevant to forest regeneration and ecosystem service provision. We also aim to determine a set of sensitive soil quality indicators to grazing pressure, so they are useful as early indicators of degradation or restoration practices' effectiveness. This study evaluated twenty soil quality indicators in two contiguous degraded forest areas with contrasting grazing pressure. We observed a substantial shift in forest structure, a reduction in tree coverage on the overgrazed sites. Overgrazing has significantly affected most soil physical, chemical, and biological quality indicators making soil conditions less suitable for seed germination and sapling establishment. We also observed an alteration in $\mathrm{C}, \mathrm{N}$, and $\mathrm{P}$ biogeochemical pools. Besides, soil physical indicators alterations suggest changes in these soils' hydrological behavior, potentially reducing water storage, availability, and increasing runoff. We show that uncontrolled grazing in native protected areas degrades soils and forest health, restricting forest regeneration and potentially accelerating erosive processes. Our results emphasized the need for an improved conservation plan for these forests that systematically evaluates and monitors livestock grazing and its direct and indirect effects, including soil quality.

Keywords : soil health, overgrazing, tree regeneration, mountainous forest, volcanic soils INTRODUCTION

Mountain forest ecosystems are a complex socioecological system where competitive land-uses, management practices, and biodiversity conservation are in a continuous quarrel (Concostrina-Zubiri et al., 2017; Renison et al., 2010). Most of the ecosystem services that forests provide, such as clean water provision, carbon sequestration, nutrient cycling, and biodiversity conservation, depend on maintaining adequate soil functioning and quality (Dominati et al., 2010; Wu, 2013). However, large areas of these natural forest ecosystems have been pushed to a limit where soil conservation and functioning are at risk. The main drivers for forest ecosystem degradation processes are timber extraction and overgrazing, which affect both soil quality and natural forest regeneration and successional processes.

In many South American mountainous areas, where grazing is a relevant activity, there have been reports of land and forest degradation (e.g., Renison et al. (2010)). In the past decades, researchers have shown strong evidence of the negative impacts of overgrazing on plant communities and a few other on soil degradation (Concostrina-Zubiri et al., 2017; Greenwood \& McKenzie, 2001; Krummelbein et al., 2009; Manzano \& Navar, 2000; Suet al.,2004). The reduction of canopy cover, the destruction of topsoil structure and soil compaction followed by a decrease in soil infiltration and chemical properties (Krummelbein et al., 2009; Steffens., 2008) induced by grazing has led to accelerated erosion and land degradation in many regions around the world (Steffens et al., 2008).

Zamorano-Elgueta et al. (2012) studied cattle activity effects Araucaria araucana (Molina) K. Koch forests in the Chilean coastal mountain range, finding that overgrazing produced soil compaction and diminished tree recruitment. On the Argentinian side of the Cordillera de los Andes, Renison et al. (2010) found that domestic livestock is indeed the primary driver of forest and soil degradation. Currently, there is no governmental regulation concerning the use of forests for pasturing animals in Chile (Dube et al., 2016). Thus, forest and soil degradation could become worse in the future decades. The control of these potentially irreversible soil degradation processes is critical for Araucaria forests as this is an endangered species (Premoli et al., 2013) with innumerable cultural and environmental value. Moreover, Araucaria is an internationally protected species in both Chile and Argentina through its listing in I appendix of the Convention on International Trade in Endangered Species of Wild Fauna and Flora (CITES).

Soil quality indicators for soil derived from volcanic materials have been relatively less studied than for other soil types, with a few exceptions (e.g., Alfaro et al. 2018, Valle and Carrasco 2018 Zuniga et al., 2015). Valle and Carrasco (2018) tested a complete set of soil quality indicators in three volcanic soils identifying a group of them sensitive to contrasting land-use changes (native forest to prairies and cropland). The main parameters highlighted for these authors were bulk density, water retention-derived properties, SOC, P-Olsen, extractable Al, and base saturation.

In this study, we assessed the effect of exotic livestock overgrazing inAraucaria forests' soil quality, using 
the relatively recently created Ralco National Reserve (Biobio Region, Chile) as a study site. This National Reserve was created for environmental conservation considering the Mapuche-Pehuenche local indigenous communities' historical use for livestock grazing and other relevant cultural services like collecting araucaria tree seed (pinon).

Here we aim to evaluate the effect of grazing in critical soil properties related to ecosystem functions that sustain forest regeneration. We also seek to identify which properties are more sensitive to this impact. We hypothesized that livestock grazing had hampered soil quality in these weakly developed volcanic soils, affecting critical functions to plant recruitment and forest health. We expect that the soil properties identified here will help build a robust and sensitive set of soil quality indicators that could alert land managers of ongoing degradation in similar ecosystems across the Andean Region.

\section{MATERIALS AND METHODS}

\subsection{Study site.}

The study was carried out at the Ralco National Preserve (37deg52'50.47” S - 51deg20'50, 90" O), specifically in the Quillaicahue River Valley with an average altitude of 1,350 $\mathrm{m}$ above sea level. The climate has a distinct snow season with a medium winter temperature below 0degC (Donoso et al., 2014), with precipitations that can hold up to $4,000 \mathrm{~mm}$ in the form of snow during winter (Veblen, 1982). The Ralco national reserve is located in a zone with the strong influence of two large volcanoes, the Callaqui (37@56'S, 71@ 26'W, 3100 m.a.s.l.) and the Copahue (37@51'S 71@10'W, 2979 m.a.s.l.). The geomorphological processes that formed this high-altitude valley consist of series of volcanic, glacial, and fluvial processes (Zaio \& Mardones, 1991). Soils have developed on interlayered pyroclastic materials and volcanic-derived fluvial deposits overlying an old basaltic-andesitic lava flow. Like most national protected areas in Chile, no comprehensive soil survey has been conducted (CONAF 1996). Therefore, before establishing the sampling plots, we carried out a general soil survey within May 2015 and May 2016, defining the prevalent soils of the Quillaicahue valley, which were classified as either Vitric hapludands and Vitrandic udortents (Soil Survey Staff, 2014).

The site presents a temperate Andean resinous forest of Araucaria and Dombeyi's beech vegetation zone (Luebert \& Pliscoff, 2006). The main tree species is Araucaria araucana, accompanied by Nothofagus dombeyi, Nothofagus obliqua, andNothofagus antarctica. The understory comprises evergreen shrubs such as Colletia spinosa, Berberis sp, and sparse grasses such asFestuca sp., which is the primary palatable grazing resource. Before creating this protected area, the historical land use was associated with the productive activities present in this region, mainly forestry and livestock grazing (Moreira-Muñoz \& Borsdorf 2014). The Ralco national reserve was established in 1987 to protect the most septentrional population of Araucaria arauca$n a$ woods alongside to its natural resources such as soil and water and allowing the rational use of these resources by the indigenous communities (CONAF 1996). Despite the conservation efforts, there has been considerable overgrazing in the communal fields during the snow-free seasons. Thus, 18 years ago, a fence was installed to separate the high grazing areas from the low grazing areas. The differences between the high and low grazing areas is mainly due to fencing and the proximity to the communal grazing fields located directly north of our study areas.

\subsection{Soil Sampling and Laboratory Analysis.}

The experimental site was divided into two areas with different grazing pressure treatments (Figure 1). The open grazing pressure area $(\mathrm{OG})$ is a communal grazing field contiguous to pastoral communities. In contrast, the controlled grazing area (CG) corresponds to a fenced field restricting the livestock's free movement, especially cows. 


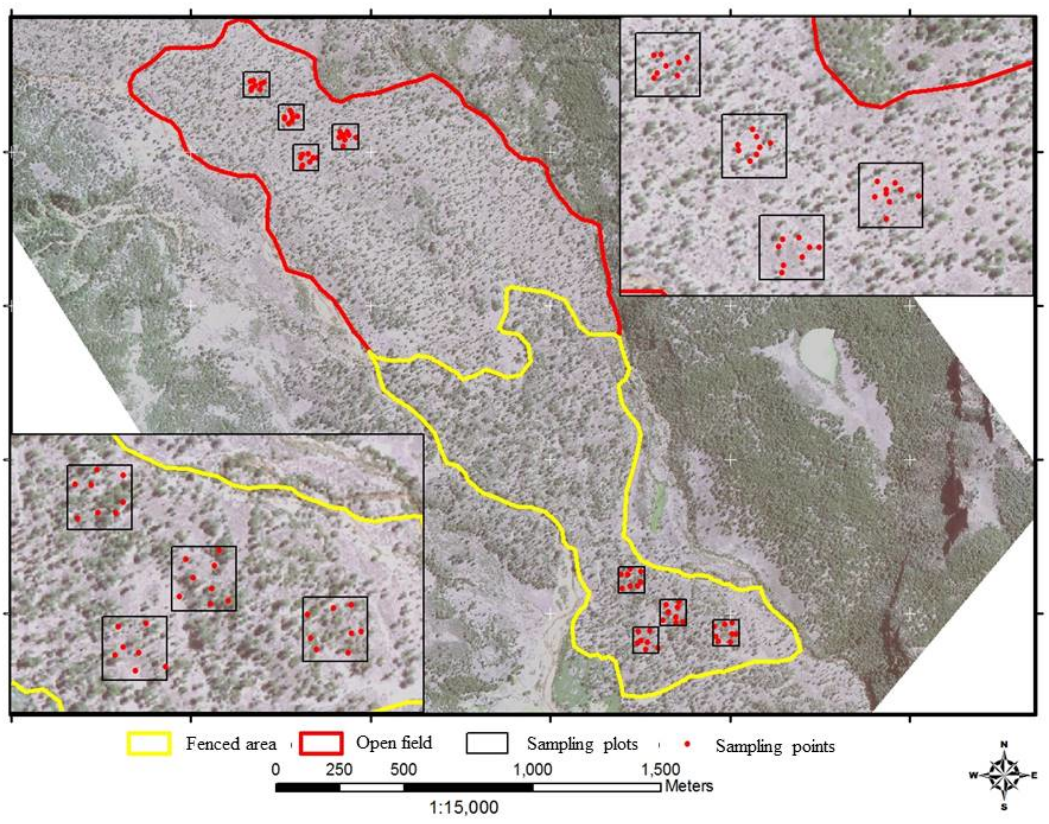

Figure 1. General map of the study site, the experimental plots, and sampling points. In the upper left and lower right corners of the map, there are zoom layers displaying the four $100 \times 100 \mathrm{~m}$ plots for each condition (OG and CG fenced area).

In each zone (CG and OG), four plots of $100 \times 100$ m were randomly established using the Geographic Data Analysis R package (Hijmans \& Van Etten, 2016). Then, at each plot, eight random sampling points were selected using the same $\mathrm{R}$ package. Once the sampling points were established in the field, in each one of the random plots, we stratified four of these points in a bare soil condition and four under Araucaria canopy to consider the heterogeneity derived from the high clustering of tree coverage in the study area (Figure 1).

In each point, and to consider the spatial variation of the soils (Kirwan et al., 2005), four auger samples per sampling point were composited at two established depths $(0-15 \mathrm{~cm}$ and $15-30 \mathrm{~cm})(\mathrm{n}=128)$. The samples were collected in sterile and hermetic bags and separated into two aliquots, one for keeping it at four ${ }^{\circ} \mathrm{C}$ for $\mathrm{NO}_{3}{ }^{-}$and $\mathrm{NH}_{4}{ }^{+}$. These were measured colorimetrically within $48 \mathrm{~h}$ after sampling (Forster, 1995; Miranda et al., 2001). The second larger aliquot was air-dried $\left(25^{\circ} \mathrm{C}\right)$ and sieved $(<2 \mathrm{~mm})$ for later analysis. Total $\mathrm{C}$ and $\mathrm{N}$ were quantified by Dumbas combustion using a SERCONC EA total CHNS analyzer. Besides, we determined $\mathrm{N}$ following the Kjeldahl distillation method (Sadzawka et al., 2006). Total, organic and inorganic phosphorus were determined following the protocol described by Bowman \& Moir (1993), using EDTA as the extraction solution. Available phosphorus was measured by the Olsen extraction method adapted by Sadzawka et al. (2006). Permanganate oxidizable carbon (POXC) was determined following the procedure described in Weil et al. (2003) as an index for easily decomposable carbon (Culman et al., 2012). Soil pH was measured with combined electrodes in both 1:1 soil/water and 1:50 NaF suspension. Cation exchange capacity (CEC) was determined following the protocol described in Sadzawka et al. (2006) buffered ( $\mathrm{pH}=7$ ) ammonium acetate as the extractant solution. All these analyses were performed at the Soil, Water, and Forest Research Laboratory of the University of Concepción (http://www.lisab.udec.cl).

For physical parameters, in each sampling point, infiltration tests were conducted using a Mini-Disk infiltrometer (Decagon (C)). Also and following the protocol described in Mohanty et al. (1994), a 750cc undisturbed soil sample was taken from the soil surface up to $10 \mathrm{~cm}$ depth and carefully transported into the laboratory for soil saturated conductivity measurements $\left(\mathrm{K}_{\mathrm{sat}}\right)$ using the "Constant-Head" method (Black et al.,1965). Following the $\mathrm{K}_{\mathrm{sat}}$ measurements, the samples were analyzed for soil bulk density, particle density (Blake \& 
Hartge, 1986), texture (Day, 1965), and water holding capacity as described in Burt (2004). Also, undisturbed soil samples were taken at each sampling point from the top 5 soil $\mathrm{cm}$ and used to estimate aggregates stability using a wet sieving apparatus (Eijkelkamp (B) following the methodology described by Kemper \& Rosenau (1986) and the adaptation described in Rivera \& Bonilla (2020) for the Eijkelkamp wet sieving apparatus.

\subsection{Forest evaluation and land cover classification}

For the forest evaluation, we used a simple random sampling design using the same four 1 ha random plots per condition as sampling units, measuring every tree above $1.3 \mathrm{~m}$ height and breast height diameter (BHD) in the plot $(\mathrm{DBH}>1 \mathrm{~cm})$. Additionally, we used partial data from a paired A.araucana regeneration study project with the Chilean national forest corporation described in (Montecino et al., In Prep), which consisted of four more 1 ha random plots, which allowed us to reduce error and to represent forest stand conditions better

Forest structure was evaluated by analyzing the observed stand diameter distribution and fitting the most common probability density functions such as lognormal, negative exponential, Weibull, and gamma functions (Newton, 2007). Following goodness-of-fit indices such as the Akaike Information Criterion (AIC) and Kolmogorov- Smirnov (K-S) test to determine the best-fit diameter distribution models.

A high-resolution multispectral satellite image was used to generate an unsupervised land cover classification of the area. The image was obtained from the World View II satellite with a $0.46 \mathrm{~m}$ resolution from February 2015. These images supply great detail and geospatial accuracy, allowing to conduct an unsupervised classification in ENVI 4.7 software, using the ISODATA clustering algorithm.

\subsection{Statistical analysis.}

For each chemical and physical parameter, comparisons between treatments were carried out using a twoway ANOVA following the general linear model of the "CAR" R package (Fox et al., 2012), followed by posthoc multiple comparisons (LSD test). All the data was checked to meet the assumptions of normality of residuals and homoscedasticity and transformed when needed. For P Olsen, we used a Negative Binomial Hurdle model approximation because of the amounts of zeros (concentrations below the detection limit). Soil data were subjected to a principal component analysis (PCA) for data ordination and reduction and distinguished if conditions were different, and determined what groups of soil indicators were more effective on differentiating grazing intensity. The data was auto-scaled previous to the PCA because of the different natural scales between variables and to attribute an equal weight to each variable (Sena et al.,2002). All statistical analysis was conducted in R (R Core Team, 2013).

\section{RESULTS}

\subsection{Forest and vegetation cover}

The dominant tree species among the study sites were Araucaria araucana and Nothofagus obliqua. Even though both conditions best fitted a lognormal distribution closely followed by a gamma distribution (S. Material 1), the dominance of small-diameter trees in both stands suggests that both stands suffered the same relatively recent disturbance event (logging and clearing for grazing) (Newton, 2007). However, the number of young individuals ( $<10 \mathrm{~cm}$ BHD) is considerably higher in the controlled grazing condition, which fits a negative exponential distribution better than $\mathrm{OG}$, which highlights an adequate regeneration and more stable growth in the controlled grazing sites (Donoso et al., 2014b) (Figure 2).

The differences between tree coverage between both conditions can be visualized in the study area's land cover classification (Figure 3). The OG condition tree coverage was 28\%, while the CG was 45.5 (a $17.5 \%$ higher). Though these sites did not show a relevant difference in the percentage of bare soil, they displayed differences on the shrubs and herbs cover, where the OG site almost doubled the CG site (44.2 versus 24\%).

\subsection{Soil physical quality indexes}


Soil particle distribution varies across the study site, but they were dominantly coarse-textured ranging from sandy loam and loamy sand for both grazing conditions (S. Material 2). Sand contents vary from 65 to $90 \%$, with very little clay content in most cases $(<5 \%)$.

None of the soil physical properties showed an interaction among factors; therefore, each factor was analyzed independently. The infiltration rate $(\mathrm{K})$ and saturated hydraulic conductivity $\left(\mathrm{K}_{\mathrm{sat}}\right)$ were significantly different between the CG condition and the OG condition (Table I).

Most soil physical variables showed a significant difference between the bare soil and the under canopy conditions, except for porosity and water holding capacity (WHC). Bulk density was significantly lower in the under-canopy condition and both saturated and unsaturated hydraulic conductivity. Additionally, the under-canopy condition showed much more stables aggregates than in the bare-soil condition

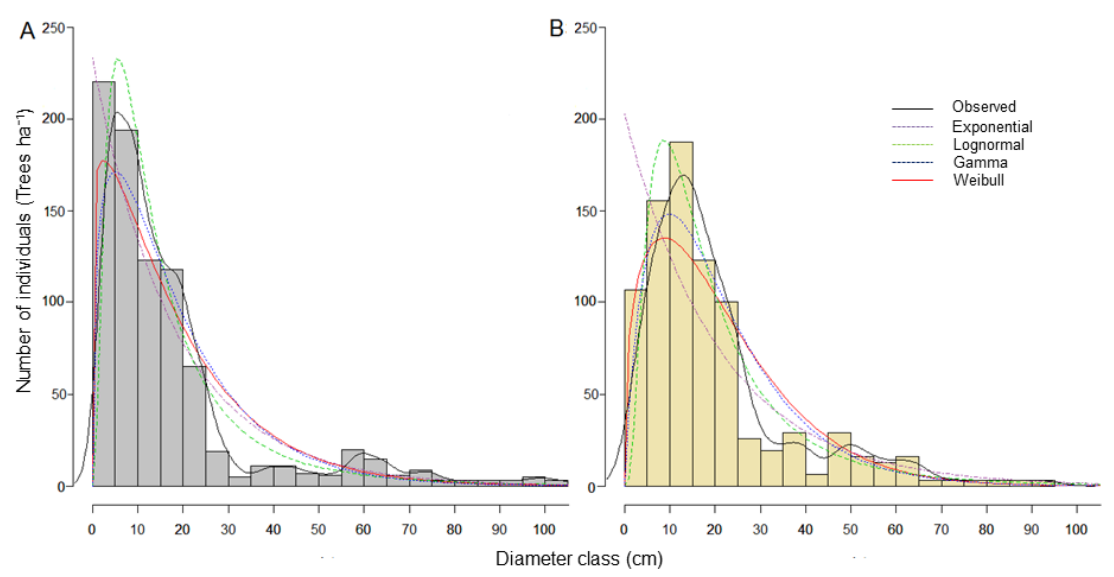

Figure 2. Observed and fitted distributions of the number of individuals ha ${ }^{-1}$ for each site (A for controlled grazing and B for open grazing) according to the different diameter classes.

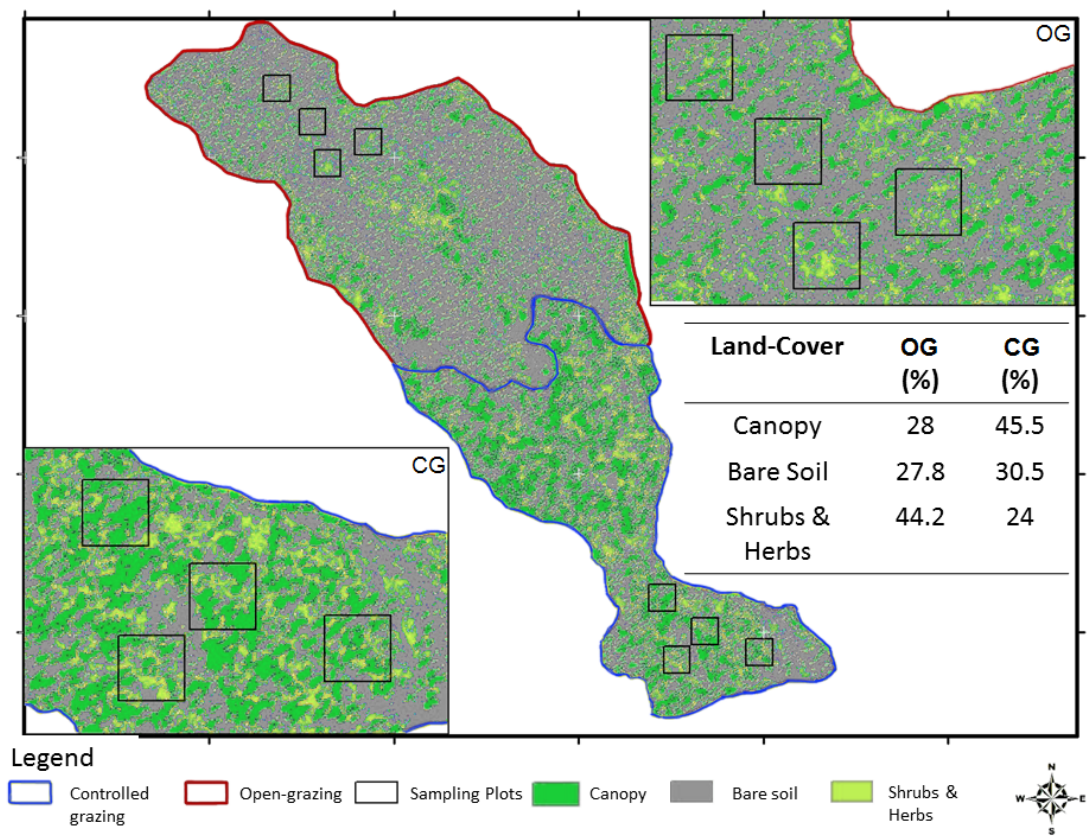


Figure 3 . Unsupervised land cover classification of the study area. The top right (OG) and left bottom (CG) layers are zoom-ins of the established plots allowing a better view of the real site conditions.

\subsection{Soil chemical quality indicators}

Total Kjeldahl Nitrogen $(\mathrm{g} / \mathrm{kg})$ showed a statistically significant difference between sites, where the nitrogen content was higher in the CG sites than in the OG sites. Both Total Carbon and Total Nitrogen (\%) were higher in the CG sites, but no significant difference was found (Table I). Available ammonium showed relevant differences among sites, where the CG sites showed lower values than in the OG area. On the other hand, nitrate was not significantly different. Total phosphorus $(\mathrm{mg} / \mathrm{kg})$ was significantly different between sites, showing higher CG values than the OG condition, mostly because of differences in the inorganic $\mathrm{P}$ content. Organic P $(\mathrm{mg} / \mathrm{kg})$ was higher in the CG sites, but no statistically significant difference was found. However, the organic $\mathrm{P}$ fraction was significantly larger under canopy across grazing conditions. Available Olsen P $(\mathrm{mg} / \mathrm{kg})$ was consistently lower in the CG site than in the OG site.

On the other hand, mineralizable $\mathrm{N}$ was higher in the $\mathrm{CG}$ sites than in the $\mathrm{OG}$ sites, but no statistically significant. Similarly, mean POXC/C showed no statistically significant difference between conditions, but it was significantly greater under the tree canopy condition. Soil $\mathrm{pH}\left(\mathrm{H}_{2} \mathrm{O}\right)$ showed a significant statistical difference between conditions, where the $\mathrm{pH}$ values in the $\mathrm{CG}$ were less acidic than in the OG site. The overall mean soil CEC was significantly different, where the CG sites' values were consistently higher than in the OG sites. All exchangeable bases were markedly higher in the CG condition, except for sodium that was higher under the OG condition.

\subsection{Selecting soil quality indicators}

To evaluate the sensitivity of different soil chemical and physical quality indicators, we performed a principal component analysis. The first three principal components were selected because they accounted for approximately $50 \%$ of the total variation. Though the contribution of the three PC to the explanation of the total variation is relatively small, it still displays loadings above 0.4 with at least three soil properties (S. Material 3). CEC, total carbon, total Phosphorus, and Inorganic Phosphorus contributed more strongly to the variability of $\mathrm{PC} 1 . \mathrm{PC} 2$ is positive related to available ammonium, available Olsen-P and Porosity, and negative related to nitrate. PC3, which explains the $11 \%$ of the total variation, have large negative loadings for the infiltration rate and K-RUSLE and positive with porosity.

The k-means clustering algorithm display that the CG site tends to differ from the OG sites even though both PC's only accounts for approximately $40 \%$ of the total variation (Figure 4 ). The chemical properties allow a fair clustering of the sites where loadings of total and inorganic Phosphorus, CEC, and Kjeldahl Nitrogen contribute the most. All the differences described above and shown in Figure 5.
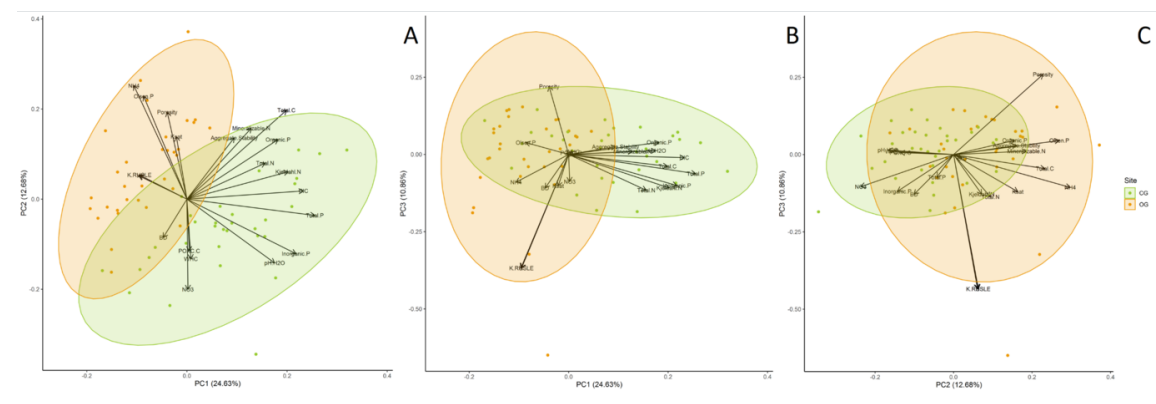

Figure 4. Biplot for PC1 x PC2(A), PC1 x PC3 (B), and PC2 x PC3 (C) with all the soil variables with their respective eigenvectors. Differences in the loadings in PC1 allow to cluster by controlled grazing sites $(\mathrm{CG})$ and the open grazing sites (OG). 


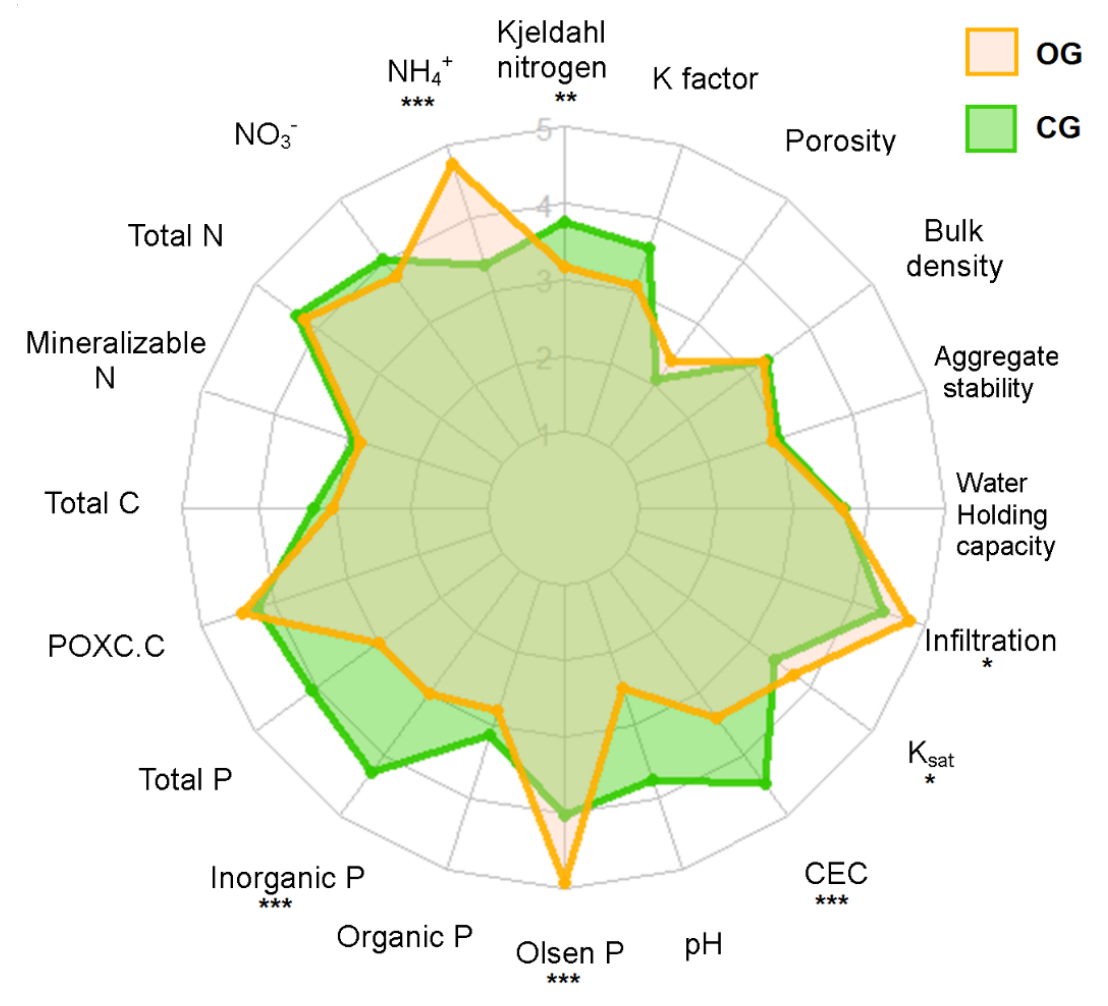

Figure 5. Radar chart includes all the measured variables scaled by the min-max method to visualize better the principal differences among the controlled grazing sites (CG) and the open grazing sites (OG). "** [?] 0.05 , “**" [?] 0.01, "****"[?]0.001 according to the two-way ANOVA results (Table 1).

\section{DISCUSSION}

Opposite to what has been reported elsewhere, most of the soil's physical properties did not respond very strongly to augmented grazing pressure. For example, soil bulk density has been used widely as an indicator of soil compressing effect caused by overgrazing, especially in the topsoil; however, the evaluated sites did not display this behavior (Donkor et al., 2002; Greenwood \& McKenzie, 2001; Manzano \& Návar, 2000; Willatt \& Pullar, 1984). The lack of differences in soil bulk density (Table I) may be explained by the coarse nature of the soil texture in these sites (Figure 2), which was dominated by sandy textures (Sandy loam, Loamy sand). Valle and Carrasco (2018) proposed bulk density as one of the best indicators for volcanic soils of Chile; however, they worked with more developed andosols with relatively finer textures. The low clay content alongside the relatively low bulk density makes the soils in our study relatively less compressive (Etana et al., 1997). Besides, grazing in this site is restricted mostly for the summer season (i.e., "veranadas" ), so at the moment of grazing perturbations, the soil water content is generally low, so compression potential is reduced (Sands et al.,1979).

Porosity should also respond to the higher mechanical stress under greater grazing pressure, negatively affecting gas flux and water flow (Dörner et al., 2012). In this study, no apparent difference in porosity was found between grazing conditions. Beck-Broichsitter et al. (2016) reported similar soil pore space values for soils derived from volcanic tephra in the southern-Andean region of Chile, showing that this soil has low-compression (0,017 PSI $\left.\mathrm{m}^{-3}\right)$. This may explain why cattle compaction is not perceptible between sites (Figure 5).

Water holding capacity is a relevant soil hydraulic property (Klute \& Dirksen, 1986) and has been proved as a useful quality indicator of grazing-induced ecological functioning changes (Greenwood \& McKenzie, 2001). 
However, like soil porosity, no significant differences were found in the water holding capacity between grazing conditions.

The results for saturated hydraulic conductivity $\left(\mathrm{K}_{\mathrm{sat}}\right)$ are typical values for sandy loam and loamy sand textures. Higher $\mathrm{K}_{\mathrm{sat}}$ values in the $\mathrm{OG}$ suggest that controlling grazing significantly diminished saturated conductivity (Table I). Experimental evidence indicates that $\mathrm{K}_{\text {sat }}$ is determined by the large pores space rather than the micropores (Alaoui et al.,2011), strongly linked to soil structure (Dorner et al., 2012). Thus, changes in saturated hydraulic conditions may help us understand possible changes in pore space's continuity and distribution (Cuevas et al., 2013). The effect of cattle trampling causes a predisposition for finer soil particle losses by wind and water erosion (Huang et al., 2007; Krummelbein et al., 2009; Su et al., 2004), causing a redistribution of pore continuity in the topsoil thus impairing water flow and conductivity. This effect is more likely to occur in the open grazing site as textures tend to be coarser; however, $\mathrm{K}_{\text {sat }}$ values were higher in this condition. Despite this apparent contradiction, $\mathrm{K}_{\text {sat }}$ was significantly higher under tree cover, a more dominant cover in the CG condition. The latter implies that even though OG had a considerably higher $\mathrm{K}_{\mathrm{sat}}$ at the sampling points, this condition may not be spatially dominant across the whole ecosystem.

Like $\mathrm{K}_{\mathrm{sat}}$, infiltration rates were significantly faster in the $\mathrm{OG}$ condition than in the CG condition. The infiltration rates $(\mathrm{K})$ were slightly slower than typical values for coarse texture soils. This could be likely the result of a strong water repellence (hydrophobicity) we observed in the field (S. Material 4). These soil types under Araucaria could show a higher water repellence caused by the accumulation of hydrophobic organic compounds as it is common for other conifer forests (Doerr et al., 2009). This effect is notably higher in soils with low clay percentages like the one in this study (Cuevas Becerra, 2006; Doerr et al., 2009; Robichaud \& Hungerford, 2000). The fact that the OG site exhibits a significantly faster infiltration rate (Table I) may be due to a lower accumulation of hydrophobic substances because of a relatively lower amount of Araucaria trees (Figure 3) and the lower canopy coverage (Figure 4). Even though a higher $\mathrm{K}_{\text {sat }}$ and infiltrability are desirable functional properties in most farmlands with fine texture soils, in this case, it could translate into excessive percolation during snowmelt and consequent excessive leaching of $\mathrm{C}$ and nutrients. This is coherent with our chemical indicators that showed lower $\mathrm{N}$ and $\mathrm{P}$ availability and lower carbon accretion in the OG and clearings conditions.

A consistent number of investigations have reported a reduction in nitrogen content induced by grazing (Steffens et al., 2008; Su et al., 2004). In our case, continuous grazing has reduced not only the total Kjeldahl nitrogen (Table 1) but also the total phosphorus concentrations (Figure 5). Also, our data suggest accelerated acidification in the open grazing condition. We also found significantly lower CEC and base saturation in both the OG and the clearing conditions. Therefore, it is clear from this data that uncontrolled grazing has reduced soil fertility, affecting not only commonly limiting elements like $\mathrm{N}$ and $\mathrm{P}$ but also exchangeable bases $(\mathrm{Ca}, \mathrm{Mg}, \mathrm{K}$ and $\mathrm{Na}$ ). This has affected productivity, reducing $\mathrm{C}$ content and forest regeneration in the OG condition (Figure 3).

The differences in tree density and ground cover between the controlled grazing conditions and the open grazing site could explain the differences we found on available phosphorus (Olsen P) between conditions. The higher organic phosphorus fraction pool in the CG condition could be considered evidence of the higher proportion of $\mathrm{P}$ absorbed, cycle, and stored by vegetation. Similarly, the significantly lower concentration of the main soil nitrogen available form in this forest (i.e., ammonium) is also the result of higher plant uptake and storage in vegetation, litter layers, and soil organic matter in the CG condition. Therefore, more densely vegetated CG sites are likely more conservative forest ecosystems with higher nutrient internal recycling than the OG conditions.

Indicators of biologic activity such as mineralizable nitrogen and POXC/C were not sensitive enough to found differences between sites. Still, if we look at the differences between cover conditions, most of our indicators (including biological) become significantly different (Table I). The increase in shrubs and herbs under open grazing areas is most likely due to combined historic logging activity, forest clearing for communal grazing, and impaired tree regeneration due to intensive grazing activity. Our analysis of coverage analysis was not able to differentiate between grasses and shrubs. However, we observed a clear difference in the 
relative abundance of grasses compared to shrub between conditions (S. Material 2), being the contribution of grasses much lower in the open grazing condition. Considering the higher removal of grass in more intensive grazing conditions (Greenwood \& McKenzie, 2001), we could explain the higher contribution of small unpalatable thorny shrubs like Colletia spinosa Lam. and bare soil conditions. The latter is direct evidence of deteriorating physical, chemical, and biological soil quality, thus accelerating soil degradation and reducing ecosystem services such as water, nutrient cycling, and biodiversity maintenance.

Even though aggregate stability is the main soil physical property that explains the OG site's clustering away from the CG site across PC 1 (Figure 5), no significant difference was found between conditions for this property (Table I, Figure 5). Aggregate Stability greatly depends on soil texture and the organic matter content (Bissonnais, 1996; Staricka \& Benoit, 1995), and as we mentioned, the soil textures for both conditions were very similar (S. Material 2) as well as soil total carbon content (Table 1). The lack of a clear deterioration aggregate stability could mislead us to conclude that livestock has no negative impact. However, like other physical properties, the aggregate stability in soils under the canopy was significantly higher than in the clearings.

Chemical indicators allow us to explain the effect of grazing (Figure 4) more clearly. Among all variables, total phosphorus and CEC ( $\mathrm{PC} 1)$, along with available ammonium and available Olsen-P ( $\mathrm{PC} 2)$, are the best indicators. These indicators are easily and routinely measured in most soil labs, and they can be useful and specific soil quality indexes for these coarse-textured volcanic soils. Moreover, the use of sensitive soil quality indicators could be a valuable assessment tool for forest managers and local communities to better plan their grazing activities in this endangered and particularly valuable forest ecosystem.

The fact that most physical and chemical indicators were significantly better under tree cover highlights the effects of more continuous and intense trapping and herbivory during livestock grazing in the clearing areas than more sporadic browsing of tree foliage and seeds under tree patches. The latter could also be the effect of higher tree litter inputs (i.e., exudates, root decay, litterfall, etc.) and consequential enhanced soil carbon accretion and nutrient cycling under the tree-covered patches than in the forest clearings. Enhancing nutrient and water availability and the consequent effect on productivity in tree and shrub patches has also been observed in similar semiarid mountainous ecosystems (Escudero et al., 2004; Kerns, et al., 2003). These tree patches present greater soil functionality (i.e., water and nutrient cycling regulation), acting as critical refuges for tree regeneration, particularly relevant for conserving endangered tree species like $A$. araucana .

\section{CONCLUSIONS}

The study area holds the most septentrional population of Araucaria araucana, making it particularly sensitive to anthropogenic disturbances and climate change. Our results indicate that uncontrolled livestock grazing, together with other anthropogenic disturbances, has reduced soil quality and forest coverage, affecting tree regeneration.

Most soil quality indicators respond to this anthropogenic forcing. Overall, livestock overgrazing has reduced hydraulic functionality, depleted nutrient reservoirs, acidified the soils, and increased erosion susceptibility, suggesting that overgrazed sites may become increasingly limiting for regeneration in coming years. Conversely, limiting grazing (18 years) has significantly favored tree regeneration, and it has helped maintain a more functional and healthy soil-forest system.

For these particularly coarse volcanic soils, soil physical indicators behave differently than expected. Thus, soil quality indexes must consider the specific expected response that soil properties and related functions will have to anthropic disturbances in contrasting soils and the consequential effect on the ecosystem services derived from them.

It is urgent to implement a combined forest restoration program in this endangered forest considering a communal livestock integrative management plan to secure the indigenous community's livelihood and soil health, and biodiversity conservation goals.

\section{ACKNOWLEDGEMENTS}


This project was funded by CONAF -Universidad de Concepcion Collaboration Project: "Evaluacion del efecto de perturbaciones antropicas en la regeneracion de bosques cordilleranos de araucaria en la region del Biobio." The authors would like to sincerely thank the administration of the Reserva Nacional Ralco for all their support and help during sampling campaigns and the local Pehuenche communities' Quepuca-Ralco and Ralco-Lepoy for allowing us to work on their ancestral lands. We would also like to thank CONAF Biobio provincial office for their support. The authors thank all students and technical personnel that provided help during the field campaign and laboratory analysis

\section{CONFLICT OF INTEREST STATEMENT}

The authors have declared no conflict of interest.

\section{REFERENCES}

Alfaro, M. Dube, F. Zagal, E. 2018. Soil quality indicators in an Andisol under different tree covers in disturbed Nothofagus forests. Chilean Journal of Agricultural Research vol.78 (1) http://dx.doi.org/10.4067/S0718-58392018000100106

Alaoui, A., Lipiec, J., \& Gerke, H. H. (2011). A review of the changes in the soil pore system due to soil deformation: A hydrodynamic perspective. Soil and Tillage Research, 115, 1-15.

Beck-Broichsitter, S., Fleige, H., Goebel, M. O., Dorner, J., Bachmann, J., \& Horn, R. (2016). Shrinkage potential and pore shrinkage capacity of differently developed volcanic ash soils under pastures in southern Chile. Journal of Plant Nutrition and Soil Science, 179(6), 799-808.

Bissonnais, Y. l. (1996). Aggregate Stability and assessment of soil crustability and erodibility: I. Theory and methodology. European Journal of soil science, 47(4), 425-437.

Black, C. A., Evans, D., \& Dinauer, R. (1965). Methods of soil analysis (Vol. 9): American Society of Agronomy Madison, WI.

Blake, G., \& Hartge, K. (1986). Particle density. Methods of soil analysis: part 1—physical and mineralogical methods(methodsofsoilan1), 377-382.

Bowman, R., \& Moir, J. (1993). Basic EDTA as an extractant for soil organic phosphorus. Soil Science Society of America Journal, 57(6), 1516-1518.

Burt, R. (2004). Soil survey laboratory methods manual: USDA.

Concostrina-Zubiri, L., Molla, I., Velizarova, E., \& Branquinho, C. (2017). Grazing or not grazing: implications for ecosystem services provided by biocrusts in Mediterranean cork oak woodlands. Land Degradation \& Development, 28(4), 1345-1353.

CONAF.(1996). Plan de manejo Reserva Nacional Ralco. 191 p.

Cuevas Becerra, J. (2006). Efecto de la materia organica y el manejo sobre la hidrofobicidad de suelos volcanicos. Revista de la ciencia del suelo y nutricion vegetal, 6(2), 13-27.

Cuevas, J., Horn, R., Seguel, O., \& Dorner, J. (2013). Hydraulic conductivity variation in Chilean volcanic soils due to wheeling and management. Journal of soil science and plant nutrition, 13(3), 756-766.

Culman, S. W., Snapp, S. S., Freeman, M. A., Schipanski, M. E., Beniston, J., Lal, R., . . . Grandy, A. S. (2012). Permanganate oxidizable carbon reflects a processed soil fraction that is sensitive to management. Soil Science Society of America Journal, 76(2), 494-504.

Day, P. R. (1965). Particle fractionation and particle-size analysis. Methods of soil analysis. Part 1. Physical and mineralogical properties, including statistics of measurement and sampling(methodsofsoilana), 545-567.

Doerr, S., Woods, S., Martin, D., \& Casimiro, M. (2009). 'Natural background' soil water repellency in conifer forests of the north-western USA: Its prediction and relationship to wildfire occurrence. Journal of 
Hydrology, 371(1), 12-21.

Dominati, E., Patterson, M., \& Mackay, A. (2010). A framework for classifying and quantifying the natural capital and ecosystem services of soils. Ecological Economics, 69(9), 1858-1868.

Donkor, N., Gedir, J., Hudson, R., Bork, E., Chanasyk, D., \& Naeth, M. (2002). Impacts of grazing systems on soil compaction and pasture production in Alberta. Canadian Journal of soil science, 82(1), 1-8.

Donoso, C., Gonzalez, M., \& Lara, A. (2014). Ecologia forestal: bases para el manejo sustentable y conservacion de los bosques nativos de Chile. Valdivia, Chile. Ediciones Universidad Austral de Chile.

Donoso, S. R., Pena-Rojas, K., Espinoza, C., Galdames, E., \& Pacheco, C. (2014). Produccion, permanencia y germinacion de semillas de Araucaria araucana (Mol.) K. Koch en bosques naturales, aprovechados por comunidades indigenas del sur de Chile. Interciencia, 39(5), 338.

Dorner, J., Dec, D., Feest, E., Vasquez, N., \& Diaz, M. (2012). Dynamics of soil structure and pore functions of a volcanic ash soil under tillage. Soil and Tillage Research, 125, 52-60.

Dube, F., Espinosa Bancalari, M., Stolpe Lau, N., \& Zagal Venegas, E. (2016). Capitulo 15: Relacion de los sistemas silvopastorales con el cambio climatico y la potencial captura de carbono. LOS SISTEMAS AGROFORESTALES EN CHILE, 317.

Escudero, A., Gimenez-Benavides, L., Iriondo J.M., \& Rubio A. (2004) Patch Dynamics and Islands of Fertility in a High Mountain Mediterranean Community, Arctic, Antarctic, and Alpine Research, 36:4,518527, doi: 10.1657/1523-0430(2004)036[0518:PDAIOF]2.0.CO;2

Etana, A., Comia, R. A., \& Hakansson, I. (1997). Effects of uniaxial stress on the physical properties of four Swedish soils. Soil and Tillage Research, 44(1), 13-21. doi:https://doi.org/10.1016/S0167-1987(97)00025-1

Forster, J. (1995). Soil nitrogen. Methods in applied soil microbiology and biochemistry, 79-87.

Fox J., \& Weisberg S. (2019). An R Companion to Applied Regression, Third edition. Sage, Thousand Oaks CA. https://socialsciences.mcmaster.ca/jfox/Books/Companion/.

Greenwood, K., \& McKenzie, B. (2001). Grazing effects on soil physical properties and the consequences for pastures: a review. Animal Production Science, 41(8), 1231-1250.

Hijmans, R. J., \& Van Etten, J. (2016). raster: Geographic data analysis and modeling. R package version 2.5-8. Vienna, Austria: The R Foundation. Retrieved from https://CRAN. R-project. org/package= raster.

Huang, D., Wang, K., \& Wu, W. L. (2007). Dynamics of soil physical and chemical properties and vegetation succession characteristics during grassland desertification under sheep grazing in an agro-pastoral transition zone in Northern China. Journal of Arid Environments, 70(1), 120-136. doi:https://doi.org/10.1016/j.jaridenv.2006.12.009

Kerns, B., Moore, M., Timpson, M., \& Hart, S. (2003). Soil properties associated with vegetation patches in a pinus ponderosa-bunchgrass mosaic. Western North American Naturalist, 63(4), 452-462. http://www.jstor.org/stable/41717319

Kemper, W. D., \& Rosenau, R. C. (1986). Aggregate stability and size distribution. Methods of soil analysis: Part 1 Physical and mineralogical methods, 5, 425-442.

Kirwan, N., Oliver, M., Moffat, A., \& Morgan, G. (2005). Sampling the soil in long-term forest plots: the implications of spatial variation. Environmental monitoring and assessment, 111(1-3), 149-172.

Klute, A., \& Dirksen, C. (1986). Hydraulic conductivity and diffusivity: laboratory methods. Methods of soil analysis: part 1-physical and mineralogical methods(methodsofsoilan1), 687-734.

Krummelbein, J., Peth, S., Zhao, Y., \& Horn, R. (2009). Grazing-induced alterations of soil hydraulic properties and functions in Inner Mongolia, PR China. Journal of Plant Nutrition and Soil Science, 172(6), 
769-776.

Luebert, F., \& Pliscoff, P. (2006). Sinopsis bioclimatica y vegetacional de Chile: Editorial Universitaria.

Manzano, M. G., \& Navar, J. (2000). Processes of desertification by goats overgrazing in the Tamaulipan thornscrub (matorral) in north-eastern Mexico. Journal of Arid Environments, 44(1), 1-17.

Miranda, K. M., Espey, M. G., \& Wink, D. A. (2001). A rapid, simple spectrophotometric method for simultaneous detection of nitrate and nitrite. Nitric oxide, 5(1), 62-71.

Mohanty, B., Kanwar, R. S., \& Everts, C. (1994). Comparison of saturated hydraulic conductivity measurement methods for a glacial-till soil. Soil Science Society of America Journal, 58(3), 672-677.

Montecino, F., Rodriguez, R., Crovo, O. Aburto, F. Livestock grazing seed consumption alters structure and hampers araucaria forest regeneration. In preparation.

Moreira-Munoz, A., \& Borsdorf, A. (2014). Reservas de la biosfera de Chile: laboratorios para la sustenabilidad: Instituto de Geografia UC.

Newton, A. (2007). Forest ecology and conservation: a handbook of techniques. Oxford University Press on Demand.

Premoli, A., Quiroga, P., \& Gardner, M. (2013). Araucaria araucana. The IUCN red list of threatened species, 2013-2011.

Team, R. C. (2013). R: A language and environment for statistical computing.

Renison, D., Hensen, I., Suarez, R., Cingolani, A. M., Marcora, P., \& Giorgis, M. A. (2010). Soil conservation in Polylepis mountain forests of Central Argentina: Is livestock reducing our natural capital? Austral Ecology, 35(4), 435-443.

Rivera, J. I., \& Bonilla, C. A. (2020). Predicting soil aggregate stability using readily available soil properties and machine learning techniques. Catena, 187, 104408.

Robichaud, P., \& Hungerford, R. (2000). Water repellency by laboratory burning of four northern Rocky Mountain forest soils. Journal of Hydrology, 231, 207-219.

Sadzawka, A., Carrasco, M., Grez, R., Mora, M., Flores, H., \& Neaman, A. (2006). Metodos de analisis recomendados para los suelos de Chile. Serie actas INIA, 163.

Sands, R., Greacen, E., \& Gerard, C. (1979). Compaction of sandy soils in radiata pine forests. I. A penetrometer study. Soil Research, 17(1), 101-113.

Sena, M., Frighetto, R., Valarini, P., Tokeshi, H., \& Poppi, R. (2002). Discrimination of management effects on soil parameters by using principal component analysis: a multivariate analysis case study. Soil and Tillage Research, 67(2), 171-181.

Soil Survey Staff. (2014). Keys to soil taxonomy. Department of Agriculture. Natural Resources Conservation Service. USA.

Staricka, J., \& Benoit, G. (1995). Freeze-drying effects on wet and dry soil aggregate stability. Soil Science Society of America Journal, 59(1), 218-223.

Steffens, M., Kolbl, A., Totsche, K. U., \& Kogel-Knabner, I. (2008). Grazing effects on soil chemical and physical properties in a semiarid steppe of Inner Mongolia (PR China). Geoderma, 143(1-2), 63-72.

Su, Y.-Z., Zhao, H.-L., Zhang, T.-H., \& Zhao, X.-Y. (2004). Soil properties following cultivation and nongrazing of a semi-arid sandy grassland in northern China. Soil and Tillage Research, 75(1), 27-36.

Valle, S. R, and Carrasco, J. (2018) Soil quality indicator selection in Chilean volcanic soils formed under temperate and humid conditions. CATENA, 162, 386-395. https://doi.org/10.1016/j.catena.2017.10.024. 
Veblen, T. T. (1982). Regeneration patterns in Araucaria araucana forests in Chile. Journal of Biogeography, $11-28$.

Weil, R. R., Islam, K. R., Stine, M. A., Gruver, J. B., \& Samson-Liebig, S. E. (2003). Estimating active carbon for soil quality assessment: A simplified method for laboratory and field use. American Journal of Alternative Agriculture, 18(1), 3-17.

Willatt, S., \& Pullar, D. (1984). Changes in soil physical properties under grazed pastures. Soil Research, 22(3), 343-348.

Wu, J. (2013). Landscape sustainability science: ecosystem services and human well-being in changing landscapes. Landscape Ecology, 28(6), 999-1023.

Zaio Ferrada, D., \& Mardones Flores, M. (1991). Influencia del Volcan Callaqui en la evolucion geomorfologica de los valles Pangue y Malla. Revista Geografica de Chile Terra Australis. 35(1),101-109.

Zamorano-Elgueta, C., Cayuela, L., Gonzalez-Espinosa, M., Lara, A., \& Parra-Vazquez, M. R. (2012). Impacts of cattle on the South American temperate forests: Challenges for the conservation of the endangered monkey puzzle tree (Araucaria araucana) in Chile. Biological Conservation, 152, 110-118. doi:https://doi.org/10.1016/j.biocon.2012.03.037

Zuniga, F. Ivelic-Saez, J. Lopez, I., Huygens, D., Dorner, F. J. 2015. Temporal dynamics of the physical quality of an Andisol under a grazing system subjected to different pasture improvement strategies. Soil and Tillage Research, 145, 233-241. https://doi.org/10.1016/j.still.2014.09.014.

\section{TABLES}

Table 1. Measured soil quality indicators in relation to the site grazing treatment (open or controlled) and soil coverage condition (mean +- SE) followed by the respective P-value. Means followed by different letter $(\mathrm{s})$ across rows are significantly different $(\mathrm{p}<0.05)$ for site and condition.

\begin{tabular}{lllll}
\hline Soil Quality Indicators & Site treatment & Site treatment & Site treatment & Soil Coverage Condition \\
\hline & Open-grazing & Controlled grazing & P-value & Under canopy \\
Bulk density (g/cm3) & $0.93 \pm 0.15$ & $0.92 \pm 0.12$ & 0.86 & $0.88 \pm 0.14 \mathbf{a}$ \\
Ksat (cm/s) & $0.004 \pm 0.002 \mathbf{a}$ & $0.003 \pm 0.002 \mathbf{b}$ & $\mathbf{0 . 0 3}$ & $0.0043 \pm 0.0025 \mathbf{~ a}$ \\
Infiltration (cm/s) & $0.0032 \pm 0.005 \mathbf{a}$ & $0.0014 \pm 0.001 \mathbf{b}$ & $\mathbf{0 . 0 2}$ & $0.002 \pm 0.005 \mathbf{a}$ \\
WHC (\%) & $12.26 \pm 6.2$ & $12.65 \pm 6.1$ & 0.89 & $12.87 \pm 5.7$ \\
Aggregate Stability (\%) & $54.92 \pm 16.4$ & $55.72 \pm 12.76$ & 0.81 & $61.57 \pm 12.5 \mathbf{a}$ \\
Porosity (\%) & $57.1 \pm 10.9$ & $52.25 \pm 12.44$ & 0.11 & $55.68 \pm 14.8$ \\
Total carbon (\%) & $4.36 \pm 1.17$ & $4.71 \pm 1.31$ & 0.23 & $4.95 \pm 1.1 \mathbf{a}$ \\
Kjeldahl (mg/kg) & $2.42 \pm 0.48 \mathbf{a}$ & $2.76 \pm 0.67 \mathbf{b}$ & $\mathbf{0 . 0 1}$ & $2.74 \pm 0.6 \mathbf{a}$ \\
Ammonium (mg/kg) & $9.57 \pm 5.76 \mathbf{a}$ & $1.28 \pm 1.01 \mathbf{b}$ & $<.001$ & $6.26 \pm 5.56 \mathbf{a}$ \\
Nitrate (mg/kg) & $4.06 \pm 3.12$ & $5.32 \pm 4.04$ & 0.103 & $4.15 \pm 4.04$ \\
Total Phosphorus (mg/kg) & $360.55 \pm 55.94 \mathbf{a}$ & $519.46 \pm 124.17 \mathbf{b}$ & $<.001$ & $453.81 \pm 125.26$ \\
Inorganic Phosphorus (mg/kg) & $200.52 \pm 44.69 \mathbf{a}$ & $338.67 \pm 90.9 \mathbf{b}$ & $<.001$ & $268.76 \pm 93.6$ \\
Organic Phosphorus (mg/kg) & $160.03 \pm 39.23$ & $180.79 \pm 68.92$ & 0.11 & $185.05 \pm 64.07 \mathbf{a}$ \\
Olsen Phosphorus (mg/kg) & $4.8 \pm 5.06 \mathbf{a}$ & $0.38 \pm 0.61 \mathbf{b}$ & $<.001$ & $2.86 \pm 4.67$ \\
pH & $5.42 \pm 0.31 \mathbf{a}$ & $6.10 \pm 0.31 \mathbf{b}$ & $<.001$ & $5.91 \pm 0.51 \mathbf{a}$ \\
POXC/C & $0.13 \pm 0.03$ & $0.13 \pm 0.04$ & 0.43 & $0.14 \pm 0.03 \mathbf{a}$ \\
Mineralizable Nitrogen $(\mathrm{mg} / \mathrm{kg})$ & $14.71 \pm 5.23$ & $15.62 \pm 5.9$ & 0.47 & $17.24 \pm 4.55 \mathbf{a}$ \\
Total Nitrogen (\%) & $0.24 \pm 0.06$ & $0.27 \pm 0.12$ & 0.43 & $0.25 \pm 0.06$ \\
CEC (cmolc/kg) & $1.4 \pm 1.47 \mathbf{a}$ & $3.99 \pm 2.75 \mathbf{b}$ & $<.001$ & $3.96 \pm 2.78 \mathbf{a}$ \\
K Rusle Factor & $0.06 \pm 0.02$ & $0.08 \pm 0.05$ & 0.09 & $0.09 \pm 0.04 \mathbf{a}$ \\
\hline
\end{tabular}



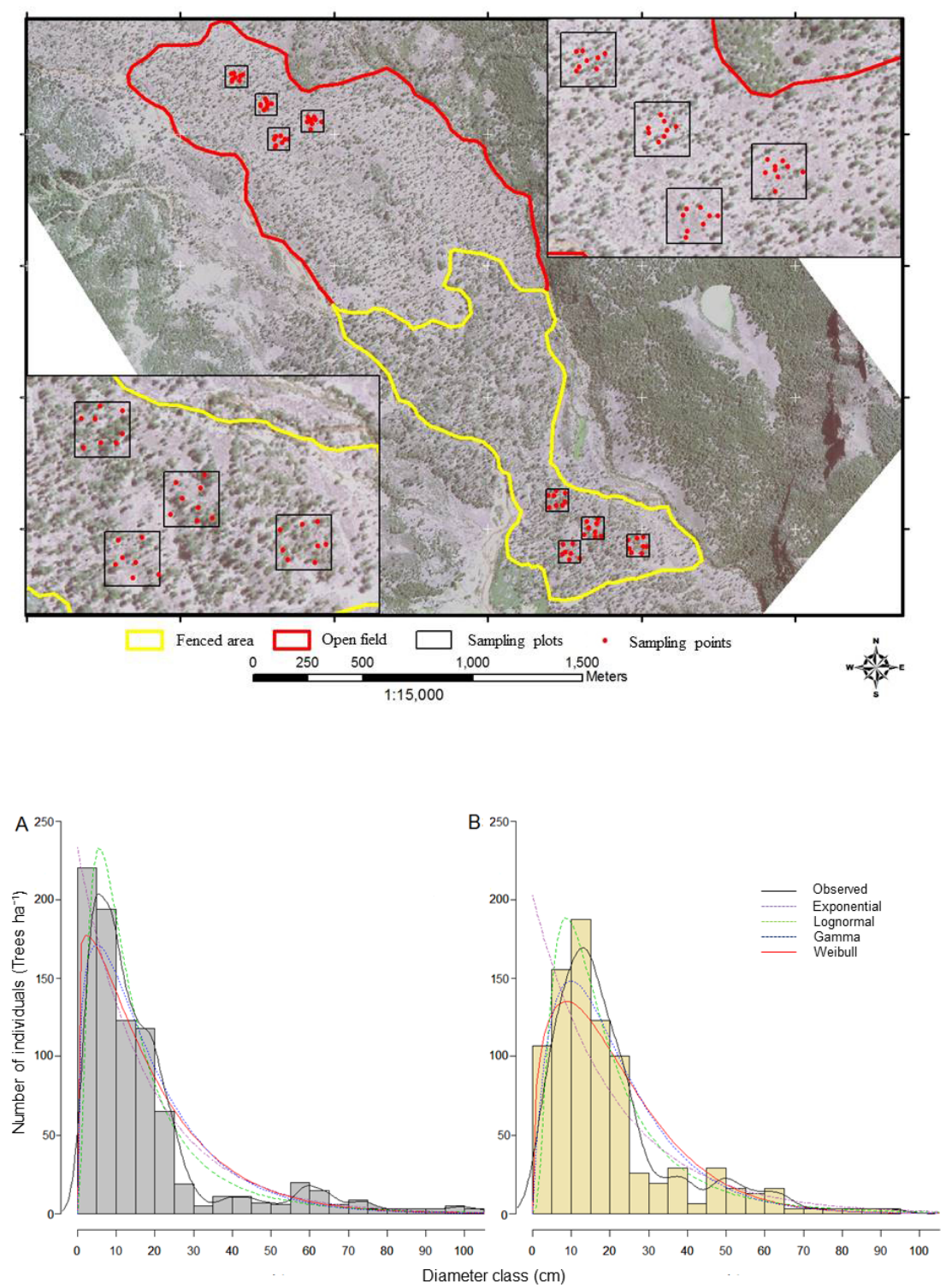

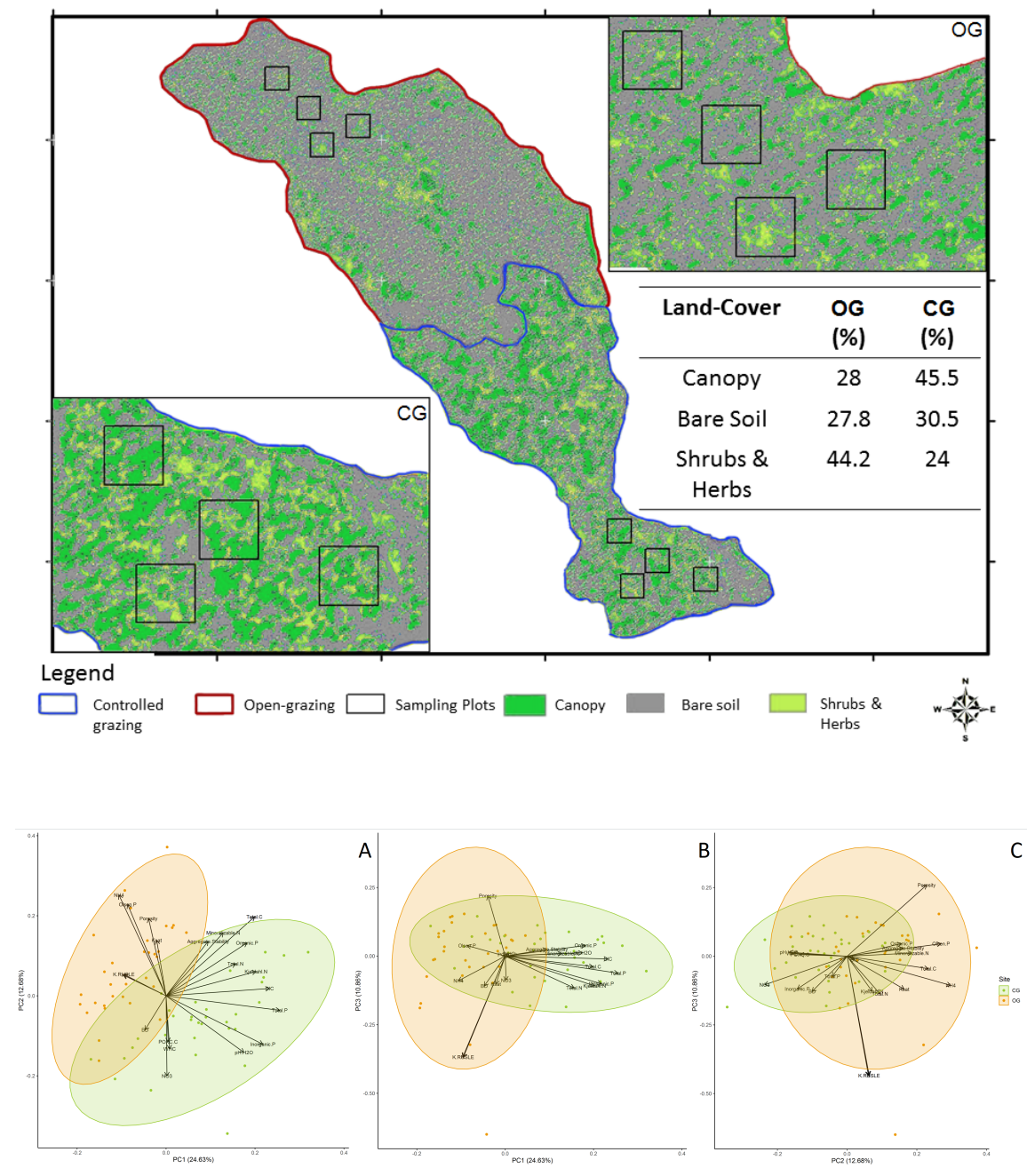


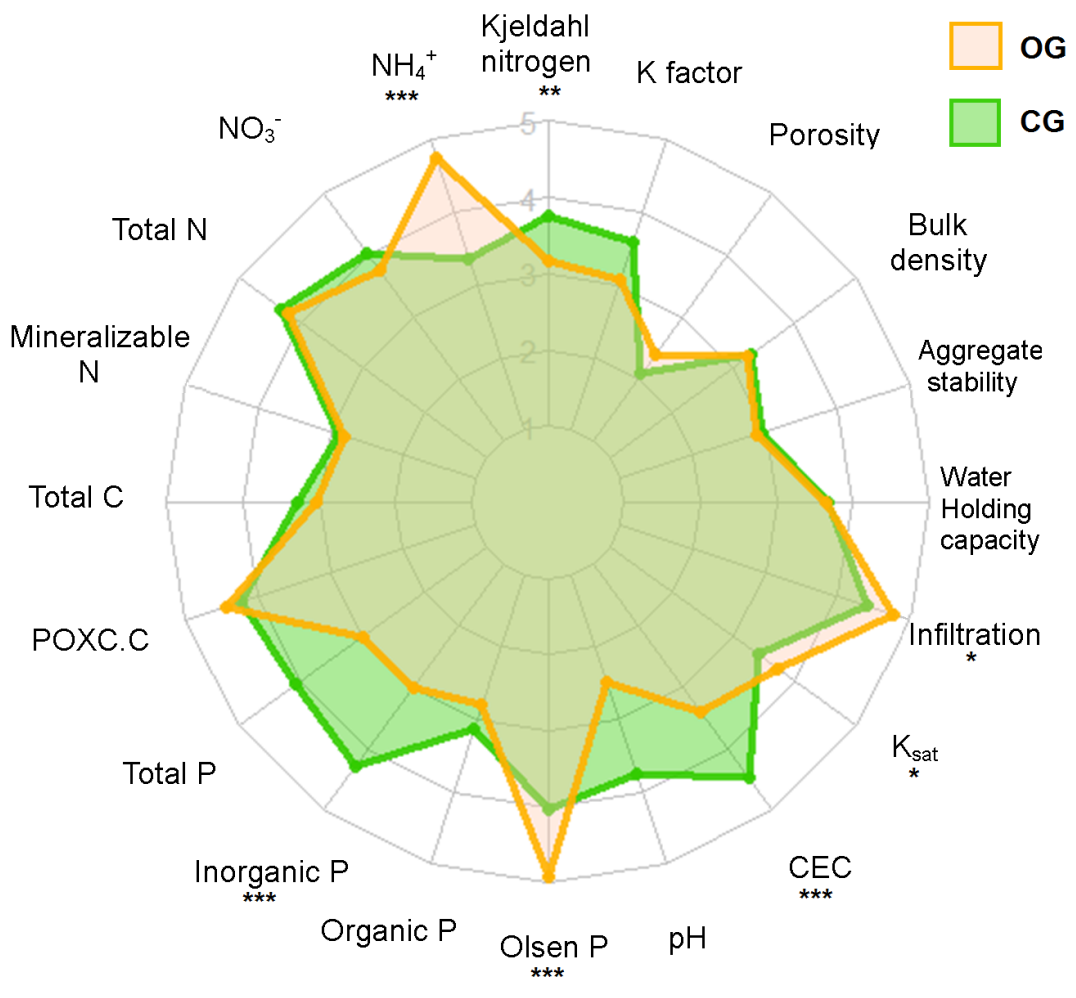

